\title{
Sensitivity study on seat belt system key factors in terms of disabled driver behavior during frontal crash
}

\author{
KAMIL SYBILSKI*, JERZY MAŁACHOWSKI \\ Military University of Technology, Faculty of Mechanical Engineering, Warsaw, Poland.
}

\begin{abstract}
Purpose: Each year, many cars (in Poland approximately three hundred) are adopted for disabled driver, to enable them to drive the car independently. The purpose of the paper is to assess the key factors which significantly influence the disabled driver behavior during a frontal crash and have the biggest impact on the safety factors. Methods: To achieve the purpose of the paper, the finite element method was used. The authors built the numerical model which includes operation of all safety systems operating in the real car (sensors, seat belts, airbag). Using this method, the authors simulated few different cases of the frontal crash of the car driven by a person with disabilities. Results: The obtained results were: displacements, velocities and accelerations of the head, pelvis and shoulders. Additional results were also loads in the neck. Based on the achieved results, several biomechanical parameters and criterions $\left(H I C, N_{i j}\right)$ were computed. Conclusions: Therefore, during car adaptation for disabled drivers using a four-point seat belts system, this parameter can be optimized to reduce forces acting on the driver chest. Higher values of the force limit reduce $N_{i j}$ and increase $H I C$ and contact forces between the dummy and seatbelts. Therefore, during designing of the pyrotechnic four-point seat belts system, the pretensioner characteristics should be analyzed taking all the driver's biomechanical parameters into account.
\end{abstract}

Key words: disability, driver, finite element method, safety, biomechanics

\section{Introduction}

Nowadays, human mobility is very important, especially for disabled and elderly people, for whom attaining greater autonomy in their everyday life helps not only to get to and from work, but also to conduct social and family life [4], [17]. The number of people with disabilities or age-related disabilities is steadily growing each year. One of the ways to increase disabled and elderly people's mobility is to enable them to drive their own cars. It is most significant outside towns, where there is no public transport or the existing transport is not adopted to their needs.

Driving a car by disabled (DD) and elderly drivers (ED) seems to be a very challenging task. The main reason is that cars are designed for people representing the majority of the population. On the global market, there is a lack of cars designed for elderly and disabled drivers. It results in the fact that their specific needs are not fully satisfied. DD and ED needs are very specific and concern many aspects, such as finding a comfortable driving position, using the car equipment, performing parking maneuvers and interacting with other drivers and signalization [7], [9]. It can be noticed that for this group it is necessary to add specific equipment which will allow them to use cars easier as well as drive more precisely and safety.

Problems concerning elderly or disabled people and limiting their mobility include, among others, reduced ability of movement. This issue is the main topic raised in many papers describing research aimed at tests and analysis of their kinematics during operation both near and inside the car [5], [6]. The greatest emphasis is put on movement strategies during getting in and out the car. It allows for definition of free space necessary to perform this process independently. It helps also understand better the difficulties of performing this process

* Corresponding author: Kamil Sybilski, Institute of Mechanics and Computational Engineering, Faculty of Mechanical Engineering, Military University of Technology, ul. gen. Sylwestra Kaliskiego 2, 00-908, Warsaw, Poland. Phone: +48 2618396 83, e-mail: kamil.sybilski@wat.edu.pl

Received: July 17th, 2019

Accepted for publication: November 28th, 2019 
by this group of drivers and to design optimal and more useful equipment supporting a driver during this process.

People with disabilities are often deprived (or have paralyzed) of one of the limbs, which reduces a number of support points. Simultaneously, mounting additional equipment (forced by disabilities) changes the driver's position. Such a kind of changes always causes displacement of the driver's mass center which, in turn, results in a change in the body behavior during dangerous situations on the road. Even the small changes is person parameters [5], such as height, a number and a type of support points or body position, significantly affect the severity of injuries sustained in an accident. In the case of elderly drivers, progressive physical changes occurring with the ageing process cause, among others, limited body stabilization. Therefore, lack in postural stabilization is an important problem. Introduction of an additional support system, e.g., four-point seat belts mounted directly to a car seat is a simple solution [12]. The advantages of these seatbelts include symmetry and ability of tight fastening. However, their disadvantage is lack of pulling out during a regular drive (which causes fatigue) and a frontal crash (which affects driver's safety). During a crash, a generated system of peak loads acting on the driver can be too high. Therefore, researchers try to find optimal seat belts characteristics [19]. A different kind of supporting system are motorized seatbelts. In paper [14], authors used numerical analysis and an experimental test to show benefits of three-points seat belts with adjustable tension. This kind of seatbelts not only increases the driver's safety, but also enhances his stability. The ideal solution seems to be a combination of both the above-described solutions into one safety system.

The authors' intention is to present a numerical model describing relationships among a disabled driver, additional equipment designed for his safety and con- venience, four-point seatbelts and an airbag system in one complex numerical simulation. Additionally, as a novelty, introduction of a pretensioner and a retractor to four-point seatbelts is considered. Based on the numerical studies, incorporating advanced FE modeling including the above mentioned issues and the influence of the various seatbelts system characteristics on the disabled driver's safety are discussed.

\section{Materials and models}

The main aim of the paper is to verify an impact of application of the pretensioner from three-point seat belts with four-point seat belts and various characteristics of their material on disabled driver's safety. A good quality of research concerning crashes require performing numerous experimental tests or numerical tests confirmed by experiments [2], [3], [11]. Validation of whole analyses or key phenomena ensure the results reliability. The advantages of numerical analysis include a possibility to carry out many tests in short time while maintaining the same conditions. It is crucial when a sensitivity study of chosen parameter of the crash behavior is verified.

The authors performed their research based on numerical analysis using a fully validated model of a car [15] and a commercial dummy model [10]. The car model was developed by introducing the seatbelts system (with fully working pretensioner and retractor), airbag system and special equipment for a disabled driver.

During the research, the authors tried to reflect all phenomena occurring in real collision. Therefore, the performed analyses were divided into three stages (Fig. 1). In the first stage, only the car model was used. The goal was to simulate a frontal crash. The main aim

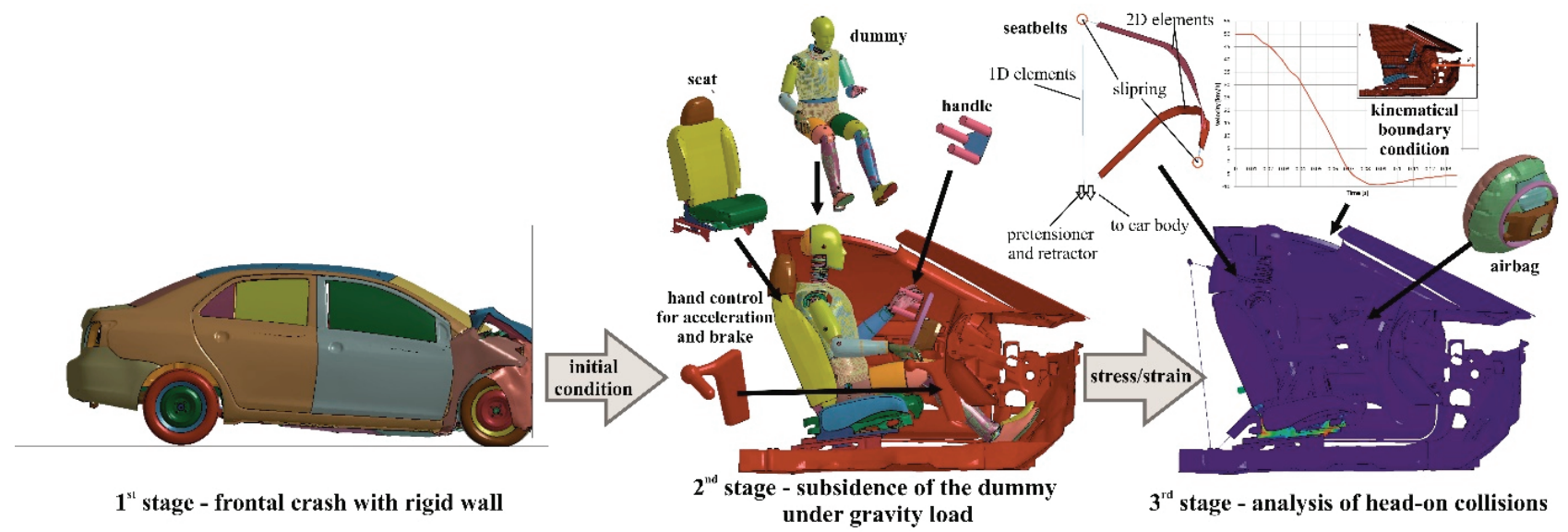

Fig. 1. Numerical research strategy 

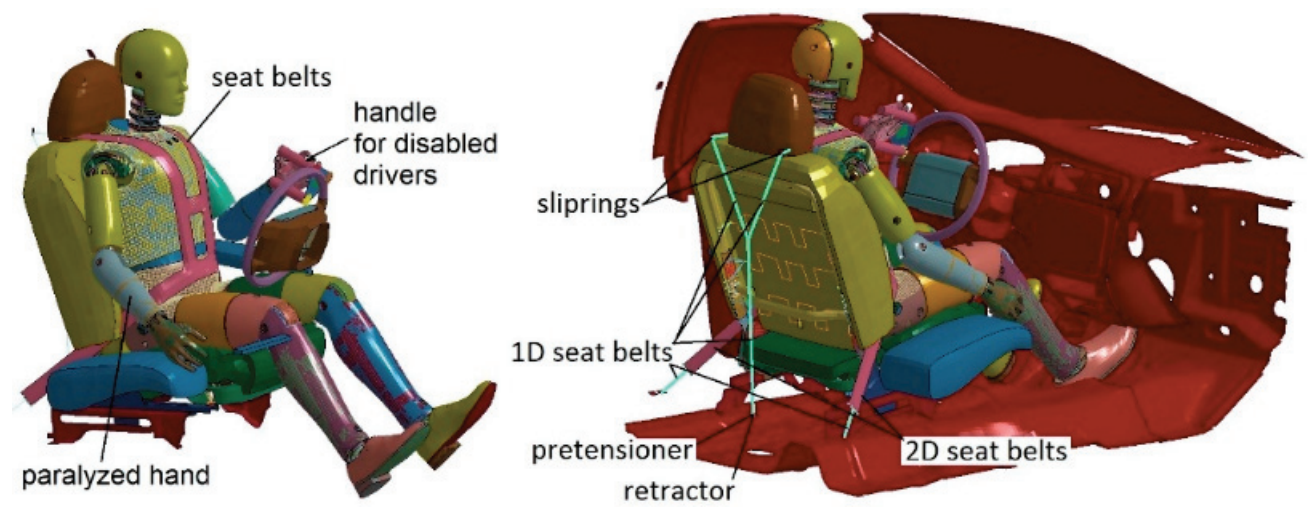

Fig. 2. Numerical model used in simulations

of this stage was to determine the course of the car body velocity change, which was used in the third stage. In the second stage, the following components were added to the car body model: a seat, special handle on the steering wheel and a dummy model. The dummy model was placed a few millimeters above the seat and limbs of the dummy were positioned near the target position. Then numerical analysis was performed and the dummy under gravity load was freely positioned on the seat, acceleration pedal, stand, steering wheel and the handle. The analysis was performed until stabilization of the dummy position and expiration of all oscillations in the model. Simultaneously, the kinetic energy was measured and, at the final stage, it was reduced to zero. The results from the subsidence process (node coordinates, stress and strain state) were used as a part of initial conditions for the third stage.

The third stage was the main part of the research. The developed final model included all elements added in the second stage and, additionally, kinematical boundary conditions determined during first stage, force interaction between the dummy the and car equipment, obtained during the second stage, as well as stress and strain resulted from this interaction, seatbelts system and airbag system. The aim of this stage was to reflect a frontal crash.

\subsection{1st stage - finite element car model}

In the first stage, a car numerical model was used [15]. The aim of this stage was to reflect a frontal crash with an initial velocity of $50 \mathrm{~km} / \mathrm{h}$. To achieve this goal, the original model was modified by adding the initial and boundary conditions (Fig. 3). Firstly, a linear velocity was added to all elements belonging to the model, excluding wheels assemblies. Then, after an appropriate conversion, the angular velocity was added to wheel elements which were mounted to the car body with rotational joints. In this manner, the wheels were rotating during the analysis, which influenced the whole crash process. It is worth noticing that, in the original model, the wheels include airbags, which are just closed volume with predefined constant value of pressure. It allow to simulate real deformation during turning.

During the analysis, the car was moving on the rigid road and act on it due to gravity load. In the front of the car, the rigid wall was defined with an appropriate contact. A frontal crash simulation was performed using LS-Dyna solver.

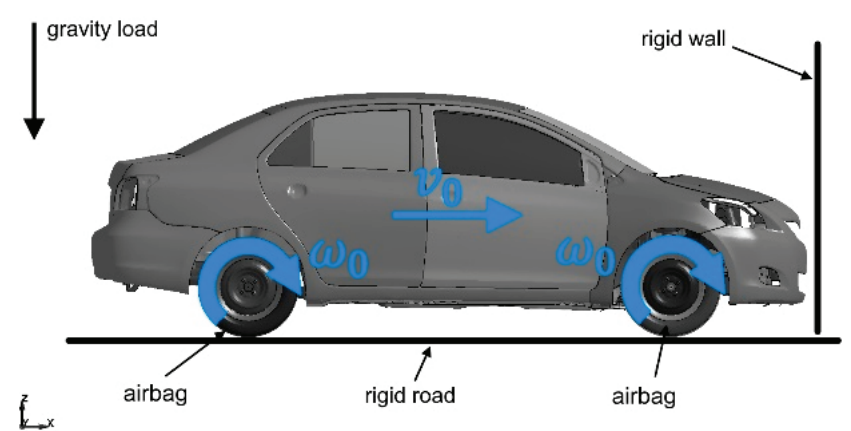

Fig. 3. Frontal crash model preparation

\subsection{2nd stage - finite element model}

The aim of the second stage was the numerical simulation of dummy model subsidence (Fig. 4). Therefore, the second numerical model was developed. It contained a quadrant of a C-segment car, seat and Dymmy Hybrid III 50th [10]. During numerical analysis, a driver with a paralyzed hand was considered. In such a case, a driver needs to use a specialized handle on the steering wheel. In the numerical model, it was reflected by using a special handle comprising three 
cylinders fixed to the triangular plate using the 1D rigid connectors.

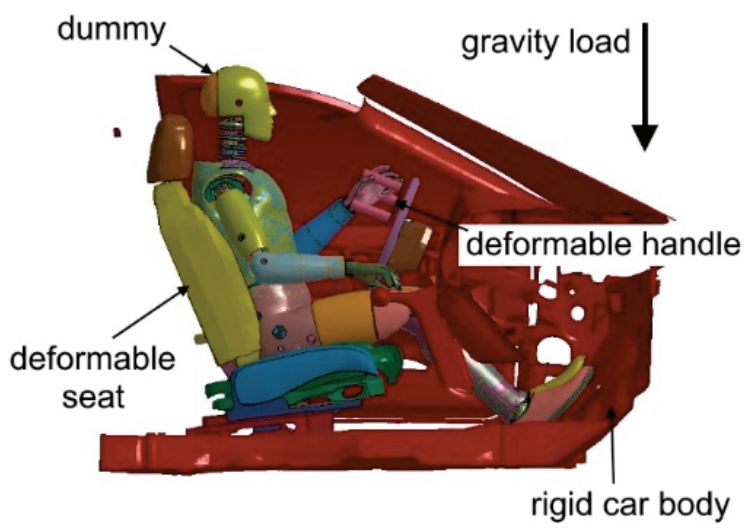

Fig. 4. 2nd stage numerical model

The car body was modeled as a rigid body. All the other elements were treated during analyses as "deformable". In the second and the third stage, it was very important to accurately describe the behavior of the seat cushions. The seat foams took important part in the subsidence process and distribution of the load acting on the dummy. The deformation of the cushion strongly influenced the friction process between the seat and the dummy, which affected the driver's whole body behavior. A proper description of the seat cushions required performing of the experimental tests, which allowed for the determination of the material parameters for the constitutive model.

Experimental tests of cushion foams were carried out according to regulation included in ASM D1621-00 and ASTM C165-00. Based on them, cuboid samples $(100.0 \mathrm{~mm} \times 100.0 \mathrm{~mm} \times 50.0 \mathrm{~mm})$ were prepared [1]. Then, the samples were uniaxially compressed using Instron 8802 testing machine. The results of the performed tests were strain vs strain curves shown in Fig. 5.

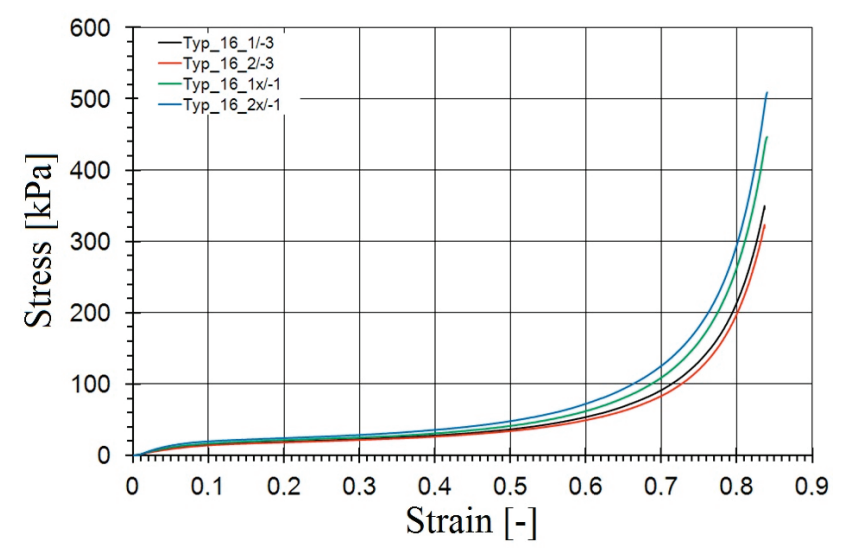

Fig. 5. Stress vs. volumetric strain curves for seat foams
In the final model, to achieve the appropriate position the dummy was placed a few millimeters over the seat and the equipment for disabled driver (Fig. 4). Then, gravity load was introduced and a contact defined. The subsidence process was simulated using explicit method.

\subsection{3rd stage - finite element model}

The third stage included a velocity course from the first stage, stress/strain state and displacements from the second stage.

\subsubsection{Seat belts}

This step was preceded by addition of the fourpoint seat belts (and necessary contact pairs) to the numerical model used in the second stage (Fig. 2). To properly describe the seat belts operation, the following parts were taken into account: sliprings (in places where the seat belts change direction), pretensioner and retractor. The slip rings enabled changing the shortening of one 1D seat belt element into elongation of another 1D seat belt element while maintaining the same tension in both elements. It also included kinematic relations and constraint applied to the nodes. The displacement of node 3 (Fig 6) depended on elongation of both connected elements and displacements of node 1 . This relation is given by the following equations:

$$
\begin{gathered}
x_{1}=x_{2}+\Delta l_{1}+\Delta l_{2}, \\
\Delta l_{1}=\frac{F \cdot l_{1}}{A_{1} \cdot E_{1}}, \quad \Delta l_{2}=\frac{F \cdot l_{2}}{A_{2} \cdot E_{2}}, \\
x_{1}=x_{2}+\frac{F \cdot l_{1}}{A_{1} \cdot E_{1}}+\frac{F \cdot l_{2}}{A_{2} \cdot E_{2}},
\end{gathered}
$$

where: $x_{1}, x_{2}$ - displacements of the ends of 1D seat belt elements, $\Delta l_{1}, \Delta l_{2}$ - elongation and shortening of connected elements, $F$ - tensioning force, $A_{1}, A_{2}$ - cross-section of elements, $E_{1}, E_{2}$ - Young's modulus of elements.

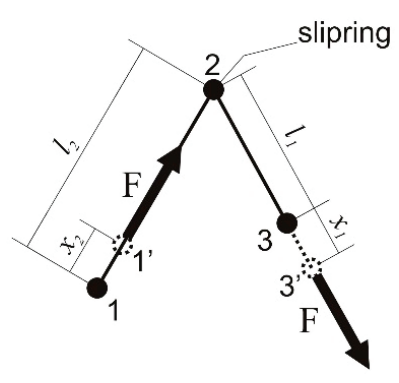

Fig. 6. Analytical model of a slipring implemented in the numerical model 
In the numerical analyses two sliprings were used. The first one to reflect seat belt buckle above shoulder and the second one buckle on the right side of the dummy close to the pelvis. Technically, in each case, two 1D seat belt elements were defined with one common node. Then, the slipring was defined with the same coordinates as common node of $1 \mathrm{D}$ seat belt elements. Finally, the special algorithm implemented in LS-Dyna code (Element_seatbelt_slipring) was defined, which holds both nodes together and transfer shortening of the first 1D seat belt element into elongation of the second one.

The proper interaction between the dummie's body and the seat belts required implementation of $2 \mathrm{D}$ elements. Due to that limitation, the seat belts needed to be modeled using a mix of $1 \mathrm{D}$ and $2 \mathrm{D}$ elements. The connection between them was modeled with a $1 \mathrm{D}$ rigid element on their ends. The pretensioner and the retractor were placed at the bottom of the seat, where a slipring and a connector with a pretensioner and a retractor, existing in a real car, can be placed. The pretensioner used in the model represented a pyrotechnic device which spins the spool of a retractor and, owing to which the seat belts are reeled in. To control this process, a pull-in versus time curve was defined. The retractor was controlled by load curves (pull in/out vs. force) for loading and an unloading phase. The retractor enables a seat belt to be paid out into a 1D belt element. It operates in one of two regimes: unlocked, when the belt material is pulled out or reeled in under constant tension, and locked, when the assumed force-pullout relationship applies. The retractor is initially unlocked and it pulls in the belt until triggering of acceleration sensors (set to $2.5 \mathrm{~g}$.). In the presented paper, the acceleration sensor was placed in the frontal part of the car body.

To describe of the seat belts behavior, an experimental test was performed. Quasi-static tensile tests were carried out using a video-extensometer and recording two markers displacement each other [16] (Fig. 7). The belt tape was mounted on the tensile machine using handles with special capstans around which the tape was wrapped (Fig. 8). The Phantom V12 fast camera was placed in front of the testing machine. The camera was synchronized with the testing machine by the testing software.

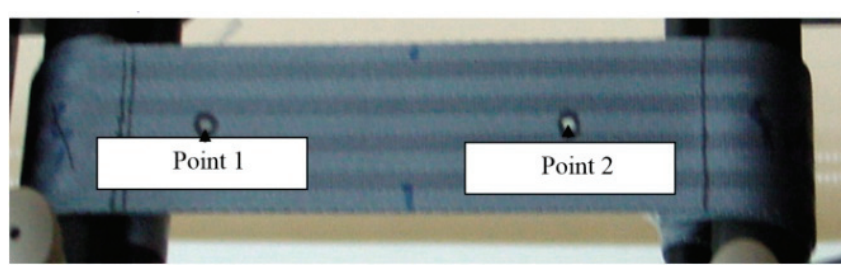

Fig. 7. Reference points on the seat belt tape [13]

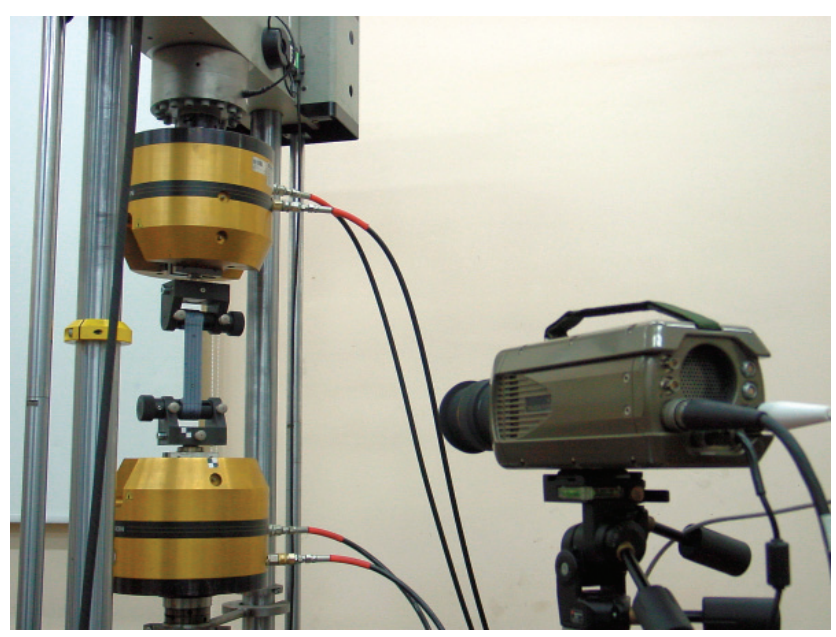

Fig. 8. Seat belt tape mounted on the testing machine [13]

As a result, a video was recorded with a rate of 25 frames per second. After the test, the results were analyzed using Digital Image Correlation (DIC) method, which allowed determination of a distance between point 1 and point 2 and, in the next stage, longitudinal deformation of the belt tape (Fig. 9).

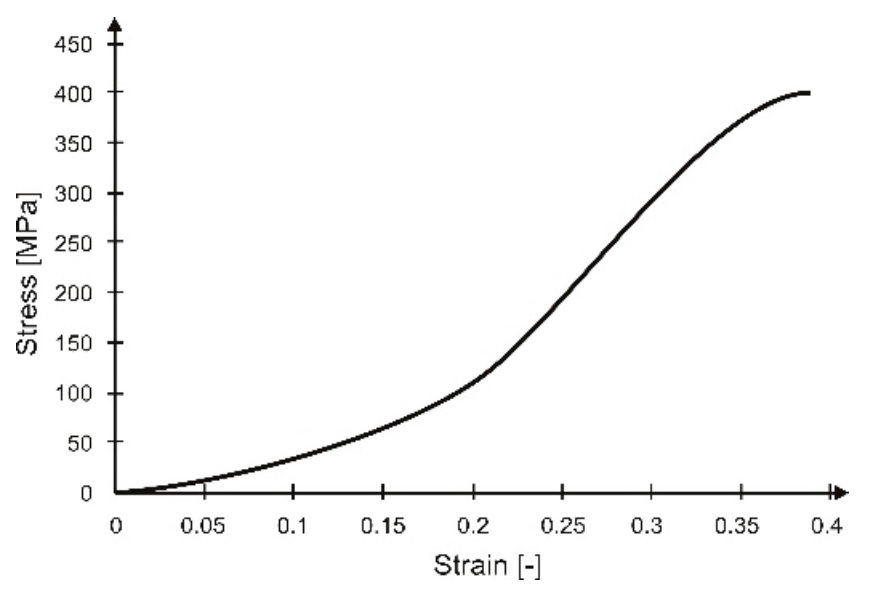

Fig. 9. Stress vs strain curve for the seat belt material [16]

In the final numerical model, the seat belt material behavior was finally modeled using two constitutive models. For 1D element simple seat belt element were used [13]. This kind of elements requires only a curve representing a force vs. displacement relationship obtained owing to a stress vs. strain curve (Fig. 9). For description of 2D elements behavior, a fabric constitutive model was used. In this case, Young's modulus (determined during the experimental test) and stress as a function of strain were adopted.

\subsubsection{Airbag}

A crucial part of car safety system is an airbag (Fig. 10). In the numerical model, there was used 
a simple airbag in which pressure is defined by equation [13]:

$$
p=\left(\frac{c_{p}}{c_{v}}-1\right) \cdot \rho \cdot e
$$

where: $c_{p}$ - heat capacity at constant pressure, $c_{v}$ - heat capacity at constant volume, $\rho$ - density, $e-$ gas specific internal energy.

The filling of the airbag was realized by a specific input mass flow rate.

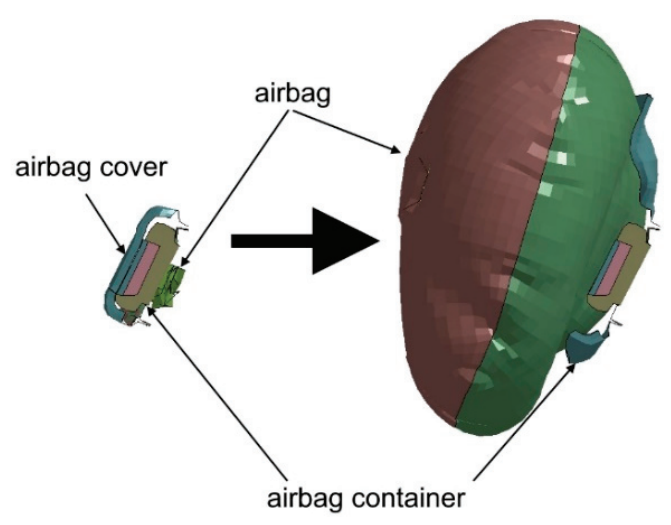

Fig. 10. Airbag parts

\subsubsection{Evaluation criteria}

Traumatic brain injury (TBI) is one of the most severe injuries in the world [18]. Currently, to estimate likelihood of head/brain injury safety standards of automotive industry are based on the Head Injury Cirterion (HIC) [8]. The magnitude of the loading effect is characterized by the $H I C$ value calculated as the maximum value of the following equation:

$$
H I C=\left\{\left[\frac{1}{t_{2}-t_{1}} \int_{t_{2}}^{t_{1}} g_{w} \mathrm{dt}\right] t_{2}-t_{1}\right\}_{\max },
$$

where: $t_{1}$ and $t_{2}-$ initial and final times of the interval, respectively, which $H I C$ attains a maximum value, $g_{w}$ - acceleration measured in $g_{s}$ (standard gravity acceleration).

To assess an influence of the loads occurred in driver's neck on his safety, Neck Injury Cirterion $\left(N_{i j}\right)$ was computed. $N_{i j}$ was calculated according to the following equation:

$$
N_{i j}=\frac{F_{z}}{F_{\mathrm{int}} \frac{M_{y}}{M_{\mathrm{int}}}},
$$

where: $F_{z}$ - axial load, $F_{\text {int }}-$ critical intercept value of the load used for normalization, $M_{y}-$ flexion/extension bending moment, $M_{\text {int }}-$ critical intercept value for the moment used for normalization.

The additional criterion was a course of shoulders rotation, which gives information about symmetry in driver's behavior during a crash.

Another verified parameter was loads acting on the driver's chest. In the presented paper, it was evaluated by calculating contact forces between the seat belts and the dummy.

\section{Results}

\subsection{First stage}

In the first stage, a frontal crash into a rigid wall was simulated. In Figure 11, the car deformation for the selected time steps was presented. During the crash, the car front part was damaged. It is a desirable effect, because, in this manner, the collision energy is dissipated and damage of the further part of the vehicle is minimized. Especially the interior part of the car which affects the safety of the driver and passengers.

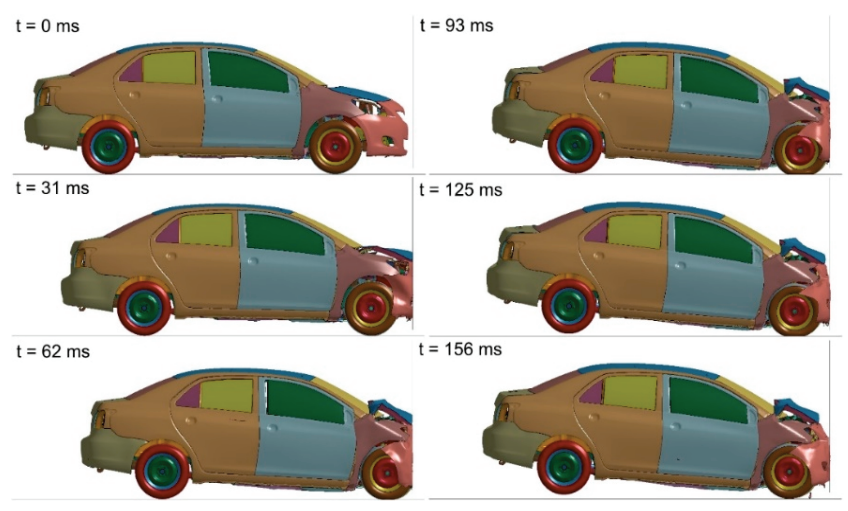

Fig. 11. Frontal crash stages

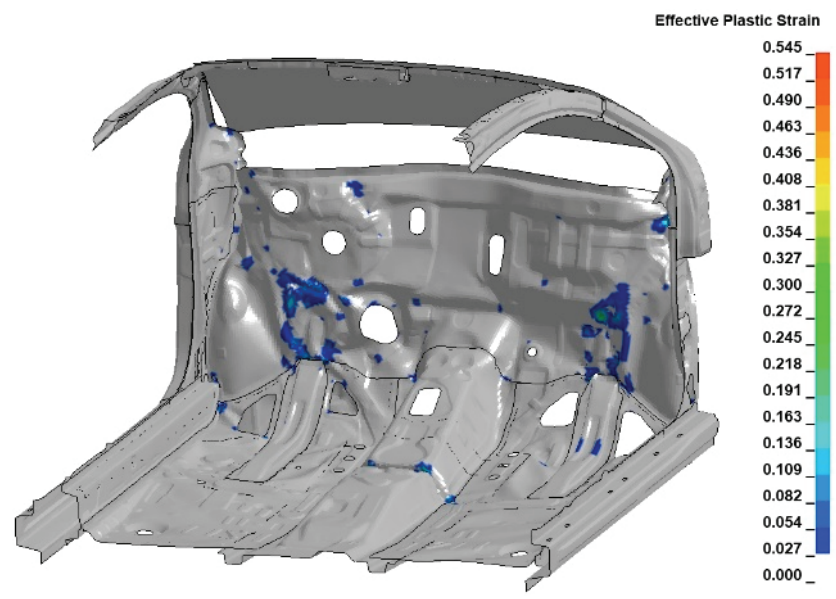

Fig. 12. Permanent deformation areas of car the interior 
In the described case, the same effect was observed. The internal part of the car was slightly deformed (Fig. 12). Only two small areas of the front bulkhead, which were connected with longitudinal crash rails, had plastic strains. Additionally the distance between the seat base and the steering wheel column base was measured. The maximum distance change value was about $40 \mathrm{~mm}$, which, taking airbag operation during crash into account, was treated as insignificant.

Therefore, the authors decided to analyze the car body in the next stages as a rigid body. It also improved calculation time consuming, because limiting the number of unknowns in dynamical motion equation. As a final result from the first stage, the velocity change course for the car interior part (Fig. 13) was taken. This course included the velocity decreasing during the first stage of the crash and the velocity increasing in the opposite direction after car reflection from the wall.

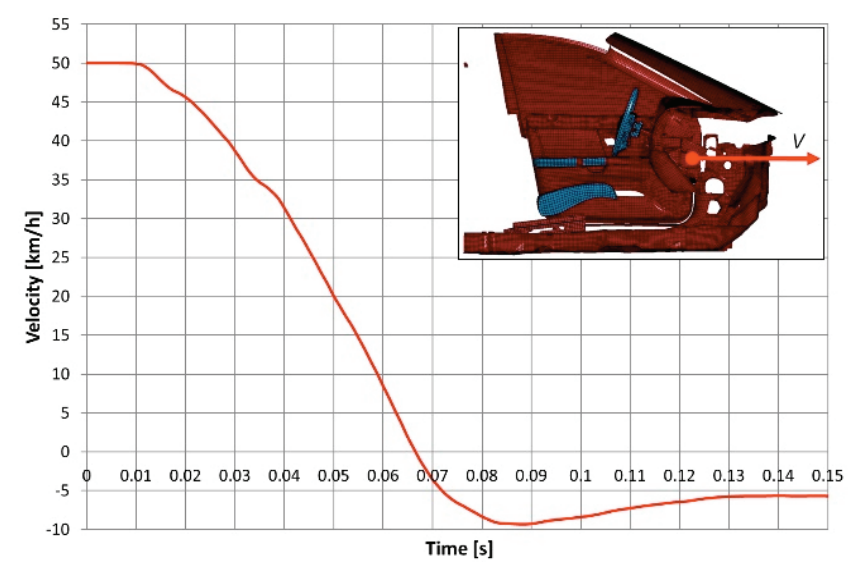

Fig. 13. Car interior velocity course

\subsection{Second stage}

In the second stage, the dummy model was placed on the seat, acceleration pedal, footrest and equipment for a disabled driver. Before the analysis, the limbs were placed near the target position to ensure the proper position after subsidence and limit stabilization time. Then, the gravity load was added. During simulation, two parameters were analyzed - displacement of $h$-point of the dummy and global kinematic energy. The first parameter gives information about oscillation of the dummy mass center, whereas the other informs about motion/oscillation in the whole analysis. In Figure 14, the course of $h$-point displacement and global energy balance were shown. It can be noticed that after $0.26 \mathrm{~s}$ the motion ended and measured kinetic energy was reduced to zero. Therefore, in all the below described results the subsidence time was set to $0.3 \mathrm{~s}$.

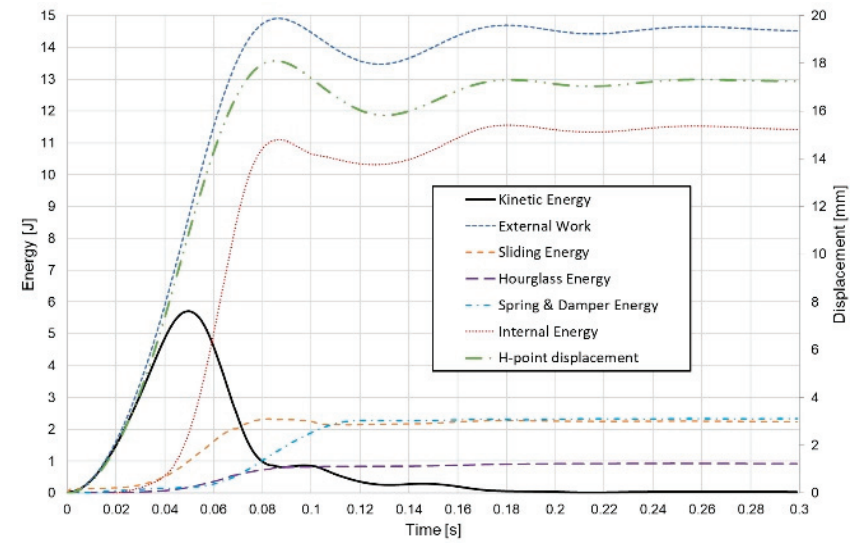

Fig. 14. H-point displacement and global energy balance

In Figure 15, the final displacements were shown. The clearance between the dummy and the car equipment was eliminated. The seat and the special equipment on the steering wheel can be observed.

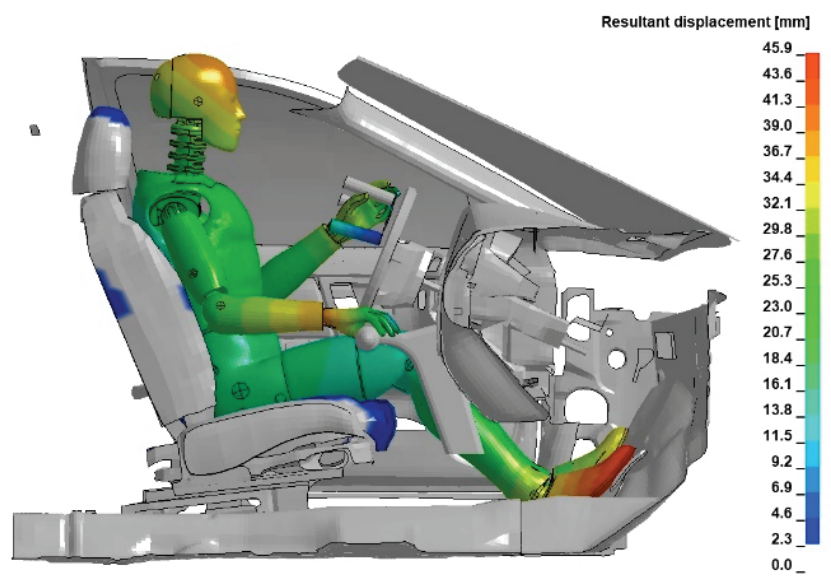

Fig. 15. Resultant displacement after subsidence

\subsection{Third stage}

In the third stage, the full frontal crash was analyzed for several parameters. In all the simulations performed, several similar stages can be specified. In the first stage, the seat belts were pulled in, which reduces clearances between the dummy and the seat belts. Next, the car velocity decreased rapidly, which activated the airbag and the seat belts sensors. It resulted in locking the retractor and caused an increase of the belt tension by the pretensioner (to the assumed level). Next, the dummy started to move towards the front of the car increasing, at the same time, the reaction between the dummy and the seat belts. Then, the car changed the moving direction, the filling airbag met the dummy head, which was accompanied by the reducing force between the seat belts and the dummy, 
and decreased the dummie's velocity. In the last stage, the car changed the moving direction. From that point, the body started moving backward.

\subsubsection{Seatbelts characteristics}

During the third stage, two factors were analyzed. The first one was the stiffness of seat belts measured during the experimental tests (Fig. 8). The authors prepared 11 variants of the model which differed only with the scale factor of the used seat belt characteristic. The scale factor changed from $50 \%$ to $150 \%$.

In Figure 16, the Head Injury Criterion (HIC15 and HIC36) were shown. The change of the seat belt characteristics do not have a significant impact on HIC.

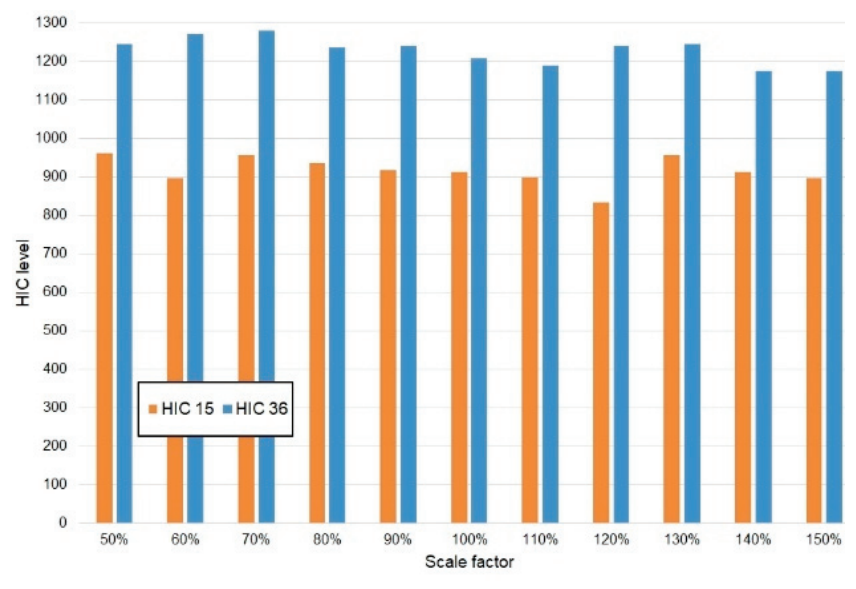

Fig. 16. Head Injury Criterion (HIC) comparison

During analyses, it was observed that the dummie's neck was strongly bent (Fig. 17). Therefore, the Neck Injury Criterion was calculated (Fig. 18). On $N_{i j}$ characteristic, two peaks of value can be indicated. The first one was a result of neck bending after preten-

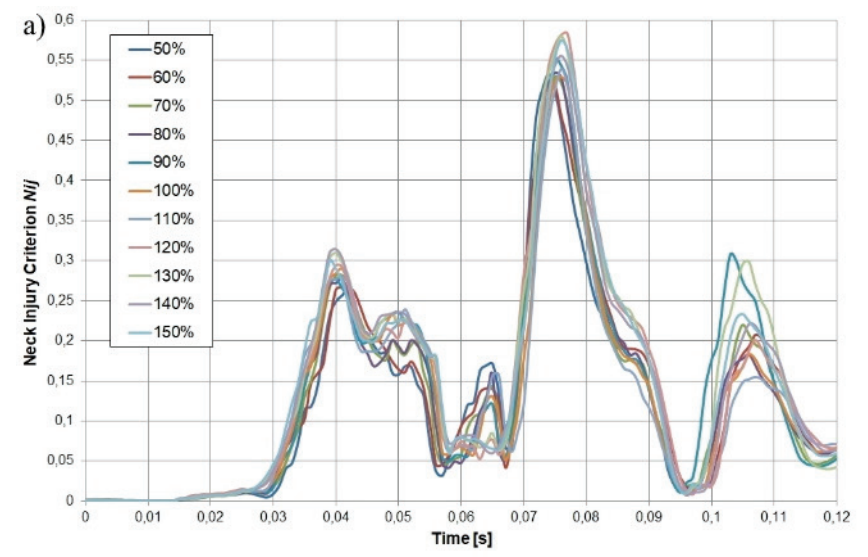

sioner operating and before contact of the dummy head with the airbag. The second one, with a higher value, was associated with ejection of the head by the airbag. For all the analyzed scale factors the, Neck Injury Criterion was lower than 0.6 , which is a satisfying result (the limit is 1.0).

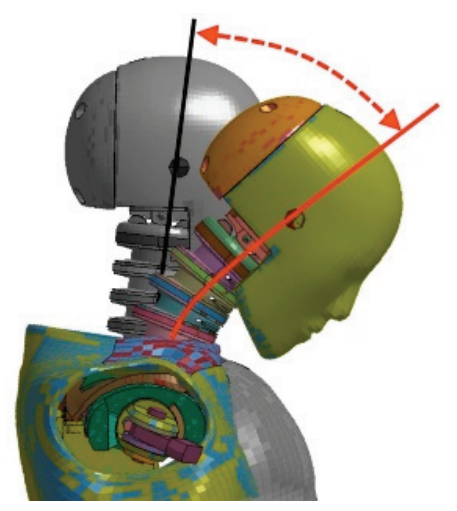

Fig. 17. Bending the neck during analysis

A change of the seat belts stiffness causes a lower decrease in the dummy body velocity before hitting the airbag. It is reflected in small changes in HIC values. However, at the same time, it caused in the analyzed variants significant changes in contact forces between the dummy and the seat belts (Fig. 19). The maximal values for $50 \%$ and $150 \%$ differ $70 \%$. For four-point seat belts system, it can reduce the chest injury.

The last measured result was shoulder rotation, which is important from the whiplash point of view. Additional equipment introduces a postural asymmetry to the driver behavior, which causes lateral displacement of the driver's head and bypassing of the car headrest. In the presented variants, rotation of the dummy shoulders was insignificant - maximum $4.3^{\circ}$ (Fig. 20).

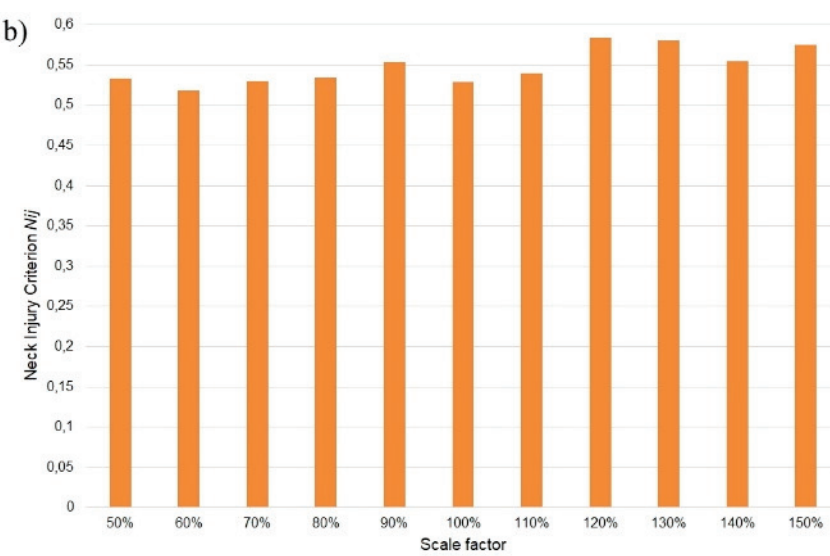

Fig. 18. Neck Injury Criterion: curves (a), maximum values comparison (b) 

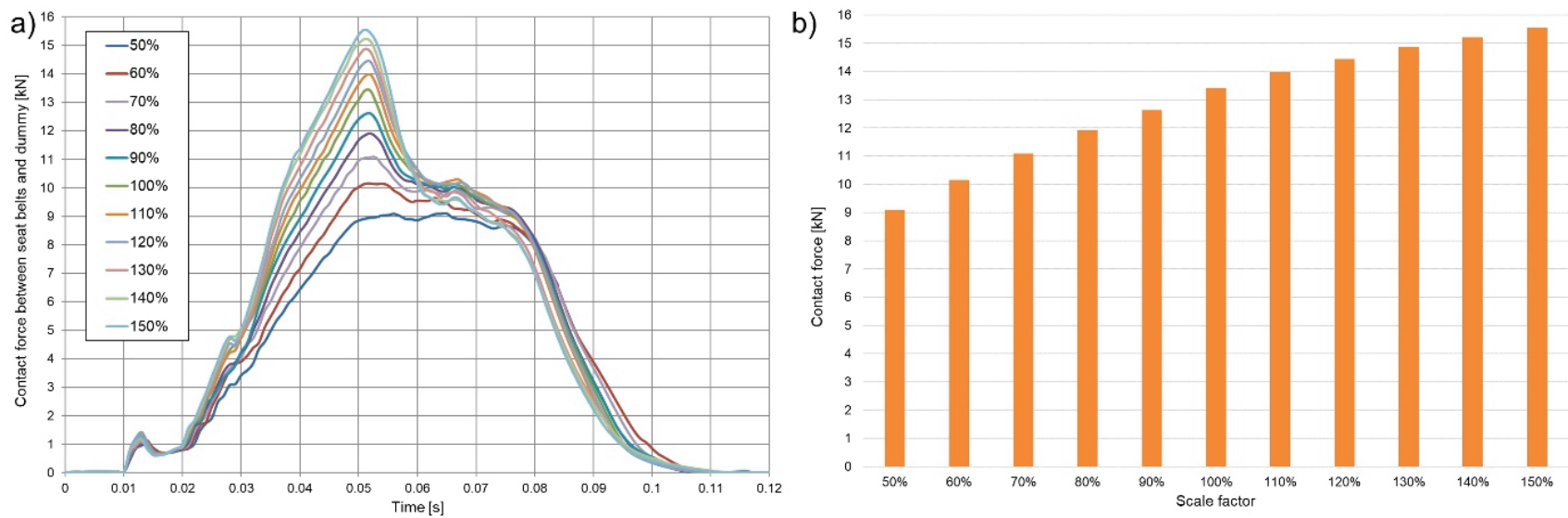

Fig. 19. Comparison of contact force between the seat belts and the dummy

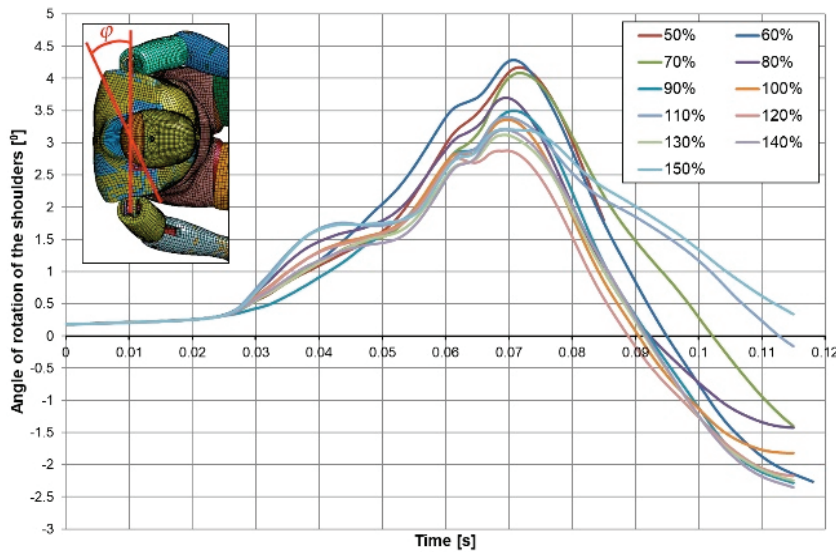

Fig. 20. Angle change during rotation of the shoulders

\subsubsection{Force limit for pretensioner}

During a crash, after seat belts triggering, a pyrotechnic pretensioner pulling in the seat belts rapidly, reducing the clearance between the seat belts and the driver. The maximum length of seatbelts shortening results from force limitation in the pretensioner construction. In the described model, two pretensioners were used: one for the left and one for the right side of the driver.

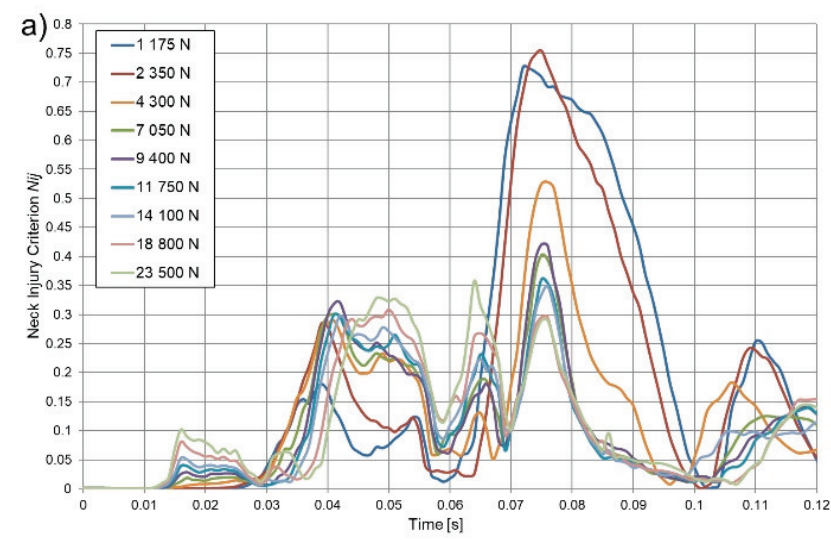

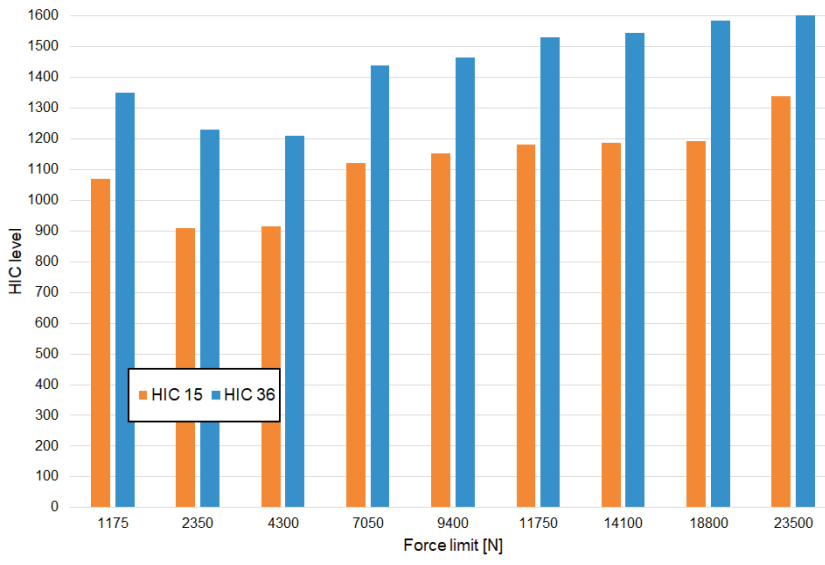

Fig. 21. Head Injury Criterion (HIC) comparison

The second analyzed parameter was the maximum force which can be generated by a pretensioner. In presented work, 9 values of the force limit were analyzed: $1175.0 \mathrm{~N}, 2350.0 \mathrm{~N}, 4300.0 \mathrm{~N}, 7050.0 \mathrm{~N}, 9400.0 \mathrm{~N}$, $11750 \mathrm{~N}, 14100 \mathrm{~N}, 18800 \mathrm{~N}$ and $23500.0 \mathrm{~N}$.

The maximum force generated by the pretensioner significantly influenced the Head Injury Criterion (Fig. 21). The lowest values were obtained for $2350.0 \mathrm{~N}$ and $4300.0 \mathrm{~N}$.

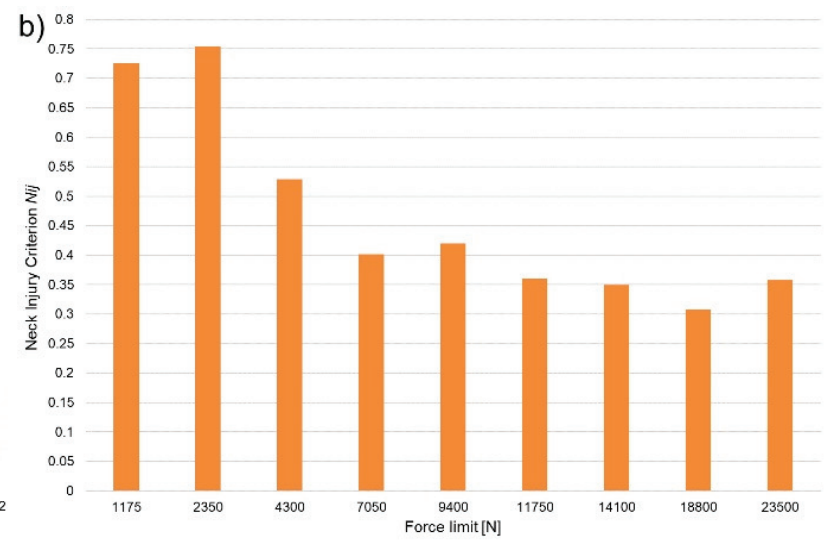

Fig. 22. Neck Injury Criterion $\left(N_{i j}\right)$ : curves (a), maximum values comparison (b) 
The force limit for the pretensioner also influenced Neck Injury Criterion (Fig. 22). For the lowest values $(1175.0 \mathrm{~N}$ and $2350.0 \mathrm{~N}), N i j$ was higher than for other variants, however only for second peak. It means that there was a stronger impact during hitting of the dummy head into airbag in these cases. It also means that the seat belts did not hold the driver tightly enough. This fact is confirmed by the contact forces between the dummy and the seatbelts shown in Fig. 23.

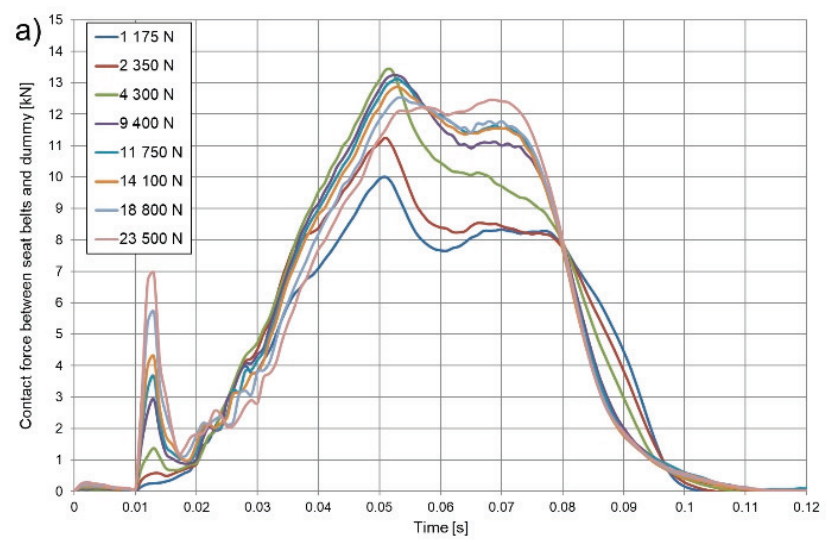

plemented, in which a single process (element) is isolated from the whole system. This gives the possibility to easily modify selected parameters and observe their impact on the isolated process and global model [5], [12]. This approach can be used for example when the reaction occurs directly after the action caused by the impulse associated with the analyzed parameter or when selected parameter has impact on one process [5], [19]. However, such the methodology is impossi-

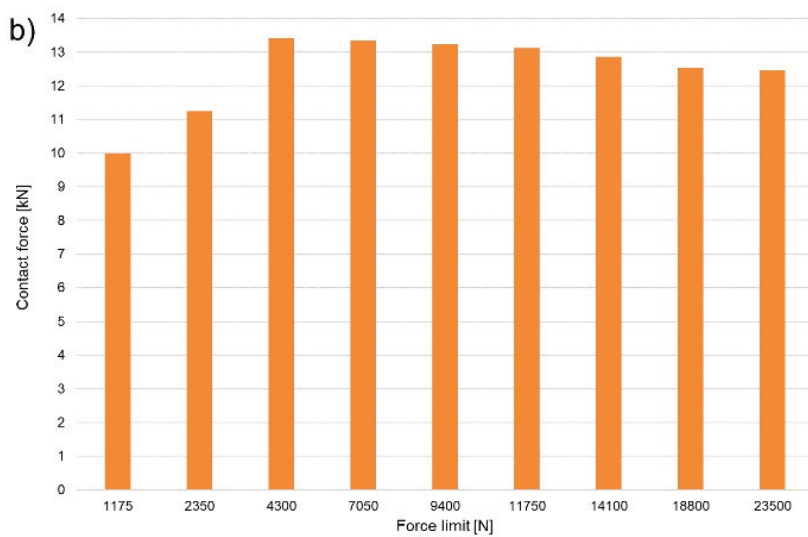

Fig. 23. Comparison of contact force between the seat belts and the dummy

Rotation of the dummy shoulder for all values of the force limit in the pretensioner was similar. The maximum value did not exceed $4^{\circ}$ (Fig. 24).

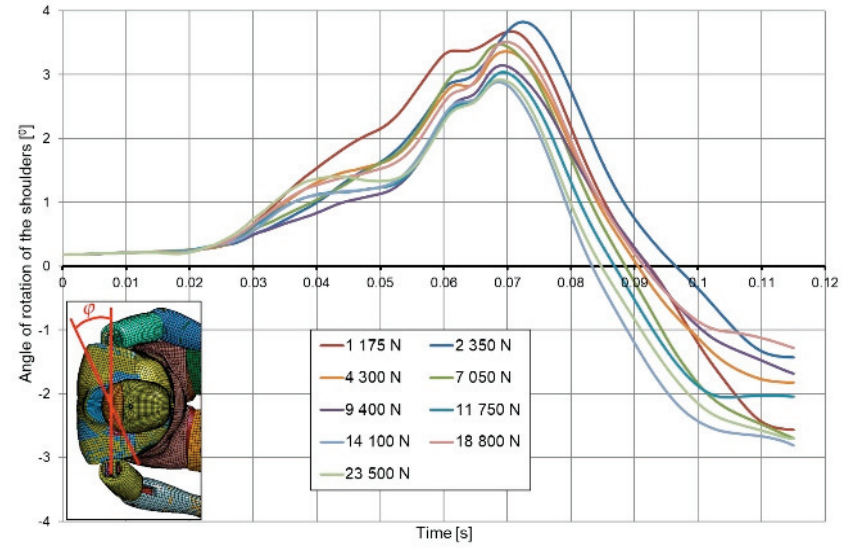

Fig. 24. Angle change during rotation of the shoulders

\section{Discussion}

The purpose of this work was to conduct sensitivity study consisting of an examination the influence of seat belt stiffness characteristic and the force limit in a pretensioner on the drivers' behavior during frontal crash. In this type of research, a special approach is im- ble to use in the presented study. During the analyzed frontal crash a number of processes which depend on the analyzed parameters and affect the final course of the measured results occur. Therefore, the authors decided to reflect the full-frontal crash scenario, taking all aspects that may affect the course of the phenomenon into account.

As a part of the work, no validation tests reflecting final numerical analyses were carried out. Instead, an approach was used in which the final numerical model uses other independently validated numerical models describing individual phenomena [2], [16]. For example, the dummy model used was validated separately in numerous tests in similar dynamic conditions [10]. The same approach was used for the car model [15] and seat belts. In the final analyses the authors combined these models to simulate frontal crash and disabled driver behavior.

Frontal collisions are very often described in many scientific journals. Nevertheless, it was found that in the literature there are no similar papers to the authors' study. Therefore, it is very difficult to relate and compare the obtained results to results other authors.

The third stage analyses included research on the impact of seat belt characteristic and force limit in tensioner on driver behavior. In the first case, HIC 15 values between 835 and 961 were obtained, respectively with a difference of $13 \%$ between the val- 
ues The calculated HIC 36 values varied from 1175 to 1280 ( $8 \%$ difference). The values changed without any trend, therefore, it cannot be stated that a change in the seat belt stiffness has a definite impact on head injuries. The similar situation was in case $N_{i j}$, for which values from 0.52 to 0.58 were obtained $(11 \%$ difference). Significant differences were observed in the case of forces acting on the chest. The greater the rigidity of the seat belt material, the greater the forces affect the chest. For the lowest stiffness the maximum force was $9 \mathrm{kN}$, and for the highest - it was over $15 \mathrm{kN}$ (70\% difference).

The value of maximum force in tensioner has a significant impact on the driver's head injury. In this case the values from 910 to 1340 were obtained for HIC15, whereas HIC36 values were measured between 1209 and 1709 . In both cases, the difference was about $30 \%$. For the lowest values of the maximum force in the tensioner, the highest values of the neck injury criterion and the lowest values of forces acting between the seat belts and the chest were obtained. This is due to the fact that for the smallest forces, the driver's body is not sufficiently held, and the driver impacts the airbag to a greater extent. In turn, for the largest forces maximally transmitted by the tensioner, no significant impact on neck injuries (values are well below the allowable value) and the forces acting on the chest. Instead, the head injury criterion HIC36 increased linearly.

\section{Conclusions}

In the presented work, the values of $H I C$ and $N_{i j}$, characteristics of contact forces between the dummy and the seatbelts, characteristics of the dummie's shoulder angle change were calculated. Based on the obtained results, it can be noticed that the HIC, $N_{i j}$ and an angle of the shoulder rotation do not depend on the seatbelts stiffness characteristic. Therefore, during adaptation of the car for disabled drivers, using a fourpoint seat belts system, this parameter can be optimized to reduce the forces acting on the driver chest. On the other hand, the HIC, $N_{i j}$ and the contact forces strongly depend on the maximum force_generated by the pretensioner during the crash. The lowest values reduce the $H I C$ value and cause-higher $N_{i j}$ values. Higher values of the force limit reduce $N_{i j}$ and increase HIC and the contact forces between the dummy and the seatbelts. Therefore, during the design of a pyrotechnic four-point seat belts system, the pretensioner characteristics should be analyzed taking into account all driver's biomechanical parameters.

\section{Acknowledgements}

This work has been performed with the support of the Interdisciplinary Centre for Mathematical and Computational Modeling (ICM) University of Warsaw under grant no. GB73-30. This support is gratefully acknowledged.

\section{References}

[1] Baranowski P., Bogusz P., DamaziaK K., Malachowski J., Mazurkiewicz L., MusZyŃski A., Analiza wpływu zastosowanego elementu energochtonnego majacego bezpośredni kontakt z głowa dziecka $w$ aspekcie minimalizacji obciażeń dynamicznych, Logistyka, 2015, 2355-2363.

[2] Baranowski P., Damaziak K., Malachowski J., MAZURKIEWICZ L., MuszyŃSKi A., A child seat numerical model validation in the static and dynamic work conditions, Archives of Civil and Mechanical Engineering, 2015, 15, 361-375.

[3] Baranowski P., DamaziaK K., Mazurkiewicz L., MALAChOWSKi J., MuszyŃsKi A., VANGi D., Analysis of mechanics of side impact test defined in UN/ECE Regulation 129, Traffic Injury Prevention, 2018, 19, 256-263.

[4] Betlej M., Radziejowska A., Bezpieczeństwo i ekologia, Autobusy, 2016, 6, 68-74.

[5] Bose D., Crandall J.R., Untaroiu C.D., Maslen E.H., Influence of pre-collision occupant parameters on injury outcome in a frontal collision, Accident Analysis and Prevention, 2010, 42, 1398-1407.

[6] Chateauroux E., Wang X., Car egress analysis of younger and older drivers for motion simulation, Applied Ergonomics, 2010.

[7] DAVIDSE R.J., Older Drivers and Adas, IATSS Res., 2006, 30, 6-20.

[8] Hazay M., Dénes D., Bojtár I., The Probability of Traumatic Brain Injuries Based on Tissue-level Reliability Analysis, Acta of Bioengineering and Biomechanics, 2019, 21, $141-152$.

[9] HeRriotTs P., Identification of vehicle design requirements for older drivers, Applied Ergonomics, 2005, 36, 255-262, DOI: 10.1016/j.apergo.2005.01.002.

[10] Humanetic Innovative Solutions Inc., Hybrid III 50th Dummy Dyna Model - technical report, 2013.

[11] Joszko K., Wolański W., Burkacki M., Suchoń S., ZiElONKA K., MuSZYŃSKi A. et al., Biomechanical analysis of injuries of rally driver with head supporting device, Acta Bioeng. Biomech., 2016, 18, 159-169.

[12] Lawton C., Cook S., May A., Clemo K., Brown S., Postural support strategies of disabled drivers and the effectiveness of postural support aids, Applied Ergonomics, 2008, $39,47-55$.

[13] LS-Dyna keyword user's manual, LSTC.

[14] Luo X., Du W., Zhang J., Safety benefits of motorized seat belt as a component in ADAS in front-end collisions, 17th IEEE Int. Conf. Intell. Transp. Syst., ITSC, 2014, 661-666.

[15] Marzougui D., Samaha R.R., Cui C.-D., Opiela K., Extended Validation of the Finite Element Model for the 2010 Toyota Yaris Passenger Sedan, National Crash Analysis Center, 2012. 
[16] Mazurkiewicz L., Baranowski P., Karimi H.R., DamaziaK K., MALACHOWSKI J., MUSZYŃSKI A. et al., Improved child-resistant system for better side impact protection, The International Journal of Advanced Manufacturing Technology, 2018, 97, 3925-3935.

[17] Monacelli E., Dupin F., Dumas C., WagstafF P., A review of the current situation and some future developments to aid disabled and senior drivers in France, IRBM, 2009, 30, 234-239.
[18] Ptak M., Ratajczak M., Kwiatkowski A., Sawicki M., Wilhelm J., Fernandes FAO et al., Investigation of biomechanics of skull structures damages caused by dynamic loads, Acta of Bioeng. Biomech., 2018, 20, 143-150.

[19] Xiao S., YANG J., CRAndall J.R., Investigation of chest injury mechanism caused by different seatbelt loads in frontal impact. Acta Bioeng. Biomech., 2017, 19, 53-62. 